\title{
Hubungan antara Critical Thinking Disposition dengan Information Literacy di Media Sosial pada Mahasiswa
}

\author{
Dhimas Fachri Aziza ${ }^{1}$ \\ Fakultas Psikologi, Universitas Muhammadiyah Malang \\ e-mail: ${ }^{1}$ dhmsfachria@gmail.com
}

\begin{abstract}
The development of technology and information in this era has made information and science inevitably overflow through social media. This situation is supported by the development of technology such as the existence of computers and internet networks in private, thus makes everyone can easily access information in anywhere and anytime. Nonetheless, information is considered a need for those who relies it in daily life, especially college students. Therefore, it is important to develop ability to find and sort information or scientific reference sources and critical thinking disposition ability to see whether the information is what we really want. The purpose of this study is to examine the relationship between critical thinking disposition and information literacy among students on social media. The sampling technique uses random sampling techniques. The research subjects were 18-24 year old students totaling 269 student. The data was collected using critical thinking disposition scale consisting of 3 aspects which were stated by Ricketts and Rudd namely engagement, cognitive maturity, and innovativeness with 23 items and information literacy scale with 13 items. Test analysis using correlation test and the results show there is a significant relationship of critical thinking disposition and information literacy among students on social media with results $(0.00<0.05)$.
\end{abstract}

KEYWORDS Critical thinking disposition, information literacy.

CITATION Aziza, D. F. (2019). Hubungan antara critical thinking disposition dengan information literacy di media sosial pada mahasiswa. Cognicia, 7, (2) 270280 .

Perkembangan teknologi dan Informasi menyebabkan jumlah informasi yang beredar semakin banyak. Keadaan tersebut didukung dengan berkembangnya teknologi yang ada semisal adanya komputer dan jaringan internet secara pribadi membuat setiap orang dapat secara mudah mengakses informasi dimanapun dan kapanpun. Informasi merupakan sebuah kebutuhan yang harus dipenuhi dalam kehidupan sehari-hari dalam masyarakat terutama mahasiswa atau pelajar. Media yang sering dipakai oleh masyarakat terutama mahasiswa atau pelajar adalah perpustakaan dan internet terutama di media sosial. Sebanyak 120 juta orang Indonesia menggunakan perangkat mobile, seperti smartphone atau tablet untuk mengakses media sosial dengan persentase 45\% (Kompas, 2018). Youtube menempati posisi pertama dengan persentase $43 \%$, facebook $41 \%$ menempati posisi kedua, Whatsapp $40 \%$ pengguna dan instagram 38\% pengguna, dengan jumlah total pengguna media sosial di seluruh dunia adalah 4 miliar (Kompastekno, 2018). 
Petumbuhan informasi melalui media sosial terus berkembang pesat sehingga menimbulkan ledakan informasi (information explotion), tidak semua informasi dapat diakses oleh semua masyarakat, karena informasi setiap jamnya dapat diperbaharui oleh sistem. Selain itu, banyaknya sistem di dalam internet yang dapat diakses oleh individu, memungkinkan banyaknya individu untuk merubah sebuah informasi dengan merubah berita yang sudah ada (Silvana, 2017), dengan banyaknya informasi yang disajikan kepada masyarakat membuat harus pintar memilih berita yang akan menjadi bahan bacaan (Naghfiroh, 2016). Banyaknya informasi yang disajikan membuat mahasiswa memang dituntut berpikir kritis terhadap isu berita yang ada di media sosial. Akibatnya dengan mudah informasi diakses banyaknya isu berita hoax yang ada di Indonesia membuat masyarakat bingung cara membedakan berita yang asli dan hoax. Maka dari itu memang masyarakat bahkan mahasiswa pun harus bisa membedakan antara berita asli dan hoax dengan cara menganalisa berita tersebut, lalu melihat sumber beritanya untuk memastikan berita tersebut dapat dipercaya atau tidak.

Menurut American Library Association kemampuan yang dibutuhkan seseorang untuk dapat menyadari kapan informasi dibutuhkan dan kemampuan untuk menempatkan, mengevaluasi, dan menggunakan informasi secara efektif disebut information literacy. Information literacy juga dapat mencakup kemampuan dalam membaca bacaan, mengutip sebuah teks. Secara sederhana information literacy merupakan kemampuan yang terdapat di dalam dirinya mengenai kapan waktu yang tepat mengetahui informasi tersebut, dan dimana informasi tersebut dapat diperoleh dengan akurat dan terpercaya (Mulyono, 2015). Information literacy adalah sebuah keterampilan yang dibutuhkan untuk mencari informasi dan menganalisa sebuah informasi (Bundy dalam Hasugian, 2009).

Kesadaran akan pendidikan information literacy di Indonesia makin meningkat terutama di sekolah maupun perguruan tinggi. Karena memang dirasa perlu bagi para siswa atau mahasiswa untuk bisa memanfaatkan sebuah informasi atau pengetahuan serta fasilitas yang menunjang untuk mendapatkan sebuah informasi atau pengetahuan semisal perpustakaan yang ada di sekolah maupun di perguruan tinggi (Wijayanti, 2012).

Menurut penelitian yang dilakukan Global Media Statistics (2016) mengungkapkan bahwa media sosial berkembang sangat pesat sejalan dengan pertumbuhan zaman dan kemudahan akses informasi yang didukung oleh kekuatan teknologi komunikasi. Media sosial memiliki pengguna aktif sebesar 79 juta, Indonesia merupakan salah satu negara teraktif di media sosial (Kompastekno, 2018). Pew Research Center membuktikan dengan penelitian yang dilakukan bahwa di Amerika Serikat bahwasanya konsumsi berita online meningkat tajam. Responden pada tahun 2011-2012 memperoleh berita secara online mencapai 50\%, sedikit lebih kecil dari televisi, tapi jauh melebihi surat kabar yang hanya mencapai $29 \%$ dan radio sekitar 33\%. (Macnamara, 2014). Responden mendapatkan berita dan informasi dari media dan jejaring sosial seperti blog, microblog (twitter) dan Facebook sejumlah 19\%, sedangkan $8 \%$ lainnya mendengarkan podcast untuk mengakses berita dan informasi (Susanto, 2017). 
Menurut penelitian yang dilakukan oleh Suyanto(2018) tentang persepsi mahasiswa terhadap kemunculan berita bohong di media sosial didapatkan bahwa sekitar 29,6\% responden mengakui sering kali mendapatkan berita-berita hoax, khususnya berita-berita yang menyinggung masalah suku, agama, ras, dan antar golongan (SARA). Sedangkan 67,9\% mengatakan jarang mendapatkan berita-berita hoax tentang sara di media sosial, sisanya $2,5 \%$ responden bahkan mengatakan tidak pernah mendapatkan berita-berita hoax tentang sara. Akan tetapi, 82,7\% responden dalam penelitian ini, mengakui bahwa berita hoax tentang sara merupakan berita yang sangat berbahaya, sehingga dapat menimbulkan kebencian ataupun konflik di tengahtengah masyarakat, dan mereka sadar akan bahayanya menyebarkan berita hoax. Sedangkan 17,3\% responden mengatakan jarang memiliki kesadaran akan bahayanya berita hoax. Bukan hanya berita hoax saja namun juga berita yang bersifat informatif, sebagai masyarakat kita juga perlu yang namanya mengidentifikasi, lalu melihat sumbernya apakah terpercaya atau tidak agar tidak terjadi penelanan informasi secara cuma-cuma.

Dari penjelasan di atas bahwa information literacy ini memang dibutuhkan oleh mahasiswa agar mereka dapat memilah sebuah informasi yang akurat dan terpercaya maka dari itu kemampuan critical thinking juga diperlukan agar mahasiswa juga mendapatkan sumber informasi yang terpercaya, karena dengan sumber informasi yang terpercaya mereka akhirnya mempunyai pemikiran yang terbuka terhadap sebuah informasi. Kemampuan critical thinking kini menjadi kemampuan yang sangat dibutuhkan dalam kehidupan, terutama dalam dunia pendidikan (Miller, 2017). Bahkan seharusnya berpikir kritis atau critical thinking ini sudah ditanamkan sejak kecil, terutama di lingkungan keluarga (Ahmatika, 2015). Namun sangat disayangkan, ketika memang sejak kecil anak-anak telah mendapatkan pendidikan berpikir kritis, banyak anak-anak tidak menggunakan kemampuan berpikir kritisnya dalam kehidupan sehari-harinya (Paparistodemou, 2015). Menjadi orang yang kritis dianggap berbahaya oleh beberapa budaya, karena mungkin memang orang-orang tersebut tidak mengetahui fungsi dari berpikir kritis (Halstead, 2004). Padahal peran siswa ketika memiliki kemampuan berpikir kritis, karena ketika para siswa memiliki kemampuan berpikir kritis akan sangat membantu dalam proses belajar baik di sekolah maupun di lingkungan sekitarnya. Sekolah telah menurunkan persyaratan pada calon siswa yang akan masuk pada periode pengajaran baru, dengan banyaknya siswa internasional yang akan masuk, namun mereka harus belajar lebih ekstra karena harapannya mereka dapat memantik siswa lainnya untuk bisa memiliki kemampuan berpikir kritis pada setiap proses pembelajaran (Miller, 2017).

Berpikir kritis atau Critical thinking adalah cara atau strategi kognitif untuk mencapai tujuan (Menurut Halpen dalam Ahmad, 2007). Disposisi adalah kecenderungan pada pola khusus intelektual (Abdurahman, 2007). Untuk jangka waktu yang lama para peneliti mendorong para siswa untuk menggunakan kemampuan berpikir kritis (Abrami, 2015). Kemampuan berpikir kritis bisa diasah dalam proses pembelajaran di kelas. Pembelajaran di kelas yang dimaksud adalah pemberian stimulus pada siswa untuk mencari konsep pengetahuan berbasis konsep dan pendalaman makna. Misalnya pembelajaran yang kontekstual, dimana peserta didik dapat membangun pengetahuannya melalui pengalaman pribadinya. Belajar 
berpikir menekankan pada proses mencari dan menemukan pengetahuan melalui interaksi antara individu dan lingkungannya (Sanjaya, 2008). Seseorang yang berpikir kritis cenderung lebih cepat dalam menangkap informasi secara relevan, memisahkan informasi yang tidak relevan serta memanfaatkan informasi tersebut untuk mencari sebuah solusi dari sebuah masalah atau mengambil keputusan (Muin, 2018). Dengan berpikir kritis seseorang dapat berpikir secara logis dan rasional, tidak terkesan mengada-ada.

Penting memang bahwasannya Critical thinking bagi mahasiswa pula. Mahasiswa adalah seseorang yang berproses dalam menimba ilmu di perguruan tinggi (Hartaji, 2012). Mahasiswa adalah kalangan muda yang berumur 19-28 tahun yang memang dalam usia tersebut adalah masa peralihan dari remaja menuju dewasa. Lalu mahasiswa juga dikenal sebagai orang yang memiliki pemikiran kritis dan cepat dalam pengambilan keputusan (Siswoyo, 2007). Karena itu, setiap perguruan tinggi yang ada di Indonesia memiliki kewajiban untuk mengafirmasi identitas dan eksistensi mereka sebagai mahasiswa secara baik, cerdas dan kritis. Menilik ke belakang, banyak cara yang dilakukan oleh mahasiswa untuk menaikkan eksistensi mereka sebagai mahasiswa.

Pada konteks zaman sekarang, upaya mengafirmasi identitas dan eksistensi dirinya secara baik, cerdas dan kritis sangat mendesak akhir-akhir ini sebagai kejadian miris yang sedang menerpa dunia kampus secara tidak langsung telah menggerus identitas diri mahasiswa. Hilangnya identitas diri dan eksistensi pada mahasiswa membuat hilangnya kepercayaan masyarakat kepada institusi perguruan tinggi. Gambaran hilangnya identitas dan eksistensi pada mahasiswa adalah mereka yang terbiasa menerima, disuapi dan tidak mau mencari lebih dalam dari sebuah informasi tersebut (Koransindo, 2017). Tepat pada bulan Februari 2019 terdapat mahasiswa asal Maumere yang mengaku bahwa dirinya menyebarkan berita hoax tentang air laut akan naik diliput melalui laman Facebooknya. Melalui laman Facebooknya ia mengakui bahwa berita yang ia sebarkan adalah hoax, sejumlah rekan-rekannya mengkomentari postingannya dan meminta agar lain kali sebelum dirinya memposting sesuatu untuk dipikirkan terlebih dahulu, agar tidak menimbulkan hal-hal yang tidak diinginkan (Kupangpos,2019).

Kejadian di atas adalah rangkaian kecil dari banyaknya peristiwa yang terjadi di negara ini, bahwa menggambarkan buramnya identitas dan eksistensi dari mahasiswa dan adanya pertentangan internal di dalam diri lembaga kampus yang idealnya merupakan sumber dan referensi keadaban intelektual publik pada kenyataannya justru mempresentasikan buramnya perilaku para calon intelektual (Kupangpos, 2016). Kehadiran mahasiswa ditengah masyarakat diharapkan dapat memberikan solusi kepada masyarakat dengan banyaknya berita hoax yang beredar di media sosial maupun media cetak serta memberikan edukasi kepada masyarakat bagaimana memilah berita yang benar dan yang bohong, lalu bisa jadi salah satu sumber informasi yang baik ketika nanti mahasiswa itu kembali ke kampung halamannya. Agar masyarakat juga mengetahui tentang berita terkini yang sedang terjadi di luar. Diharapkan pula mahasiswa yang dinilai memiliki intelektualitas yang tinggi, kecerdasan dalam berpikir, dan memiliki perencanaan dalam bertindak. Berpikir kritis dan bertindak dengan cepat dan tepat merupakan sifat yang telah melekat pada 
mahasiswa, dan mahasiswa adalah manusia yang tercipta untuk selalu berpikir dan saling melengkapi (Siswoyo, 2007). Ketika masyarakat memiliki penilalian yang tinggi dan berekspektasi terhadap mahasiswa yang tinggi dengan memiliki pemikiran yang luar biasa seperti penjelasan di atas seharusnya mahasiswa harus bisa membayar kepercayaan masyarakat dan orangtua mereka dengan belajar serius, dan menyikapi sebuah peristiwa atau berita yang tersebar di media sosial dengan bijak, sehingga tidak akan terjadi yang namanya aksi yang dapat meresahkan masyarakat, semisal demo bakar ban, merusak fasilitas, berkelahi dengan sesama mahasiswa yang itu sebenarnya dapat merugikan diri sendiri.

Berdasarkan penjelasan di atas peneliti bermaksud untuk mengetahui hubungan antara critical thinking disposition dengan literacy information di media sosial pada mahasiswa. Penelitian ini bertujuan untuk mengetahui hubungan antara kedua variabel tersebut. Manfaat teoritis dari penelitian ini adalah agar dapat memberikan kontribusi ilmu pengetahuan baru tentang critical thinking disposition dan literacy information pada mahasiswa terutama. Manfaat praktisnya sendiri adalah mampu menjadi solusi bagi mahasiswa agar dapat menganalisa, memilah berita atau bacaan terutama di media sosial dan berpikir kirtis terhadap sebuah berita yang beredar di media sosial agar tidak terjebak dengan berita atau bacaan hoax.

\section{METODE}

Subjek penelitian ini adalah mahasiswa. Pengambilan sampel dalam penelitian ini menggunakan random sampling. Jumlah subjek yang digunakan dalam penelitian ini adalah sebanyak 269 mahasiswa dengan karakteristik mahasiswa berusia 19-24 tahun dan aktif menggunakan media sosial.

Pada penelitian ini terdapat dua variabel yakni variabel bebas $(X)$ dan variabel terikat $(\mathrm{Y})$. Adapun yang menjadi variabel bebas (X) (Independent variable) yaitu critical thinking disposition dan variabel terikat $(\mathrm{Y})$ (Dependent variable) yaitu information literacy.

Critical thinking disposition adalah kecenderungan sikap untuk berpikir kritis dengan ciri seseorang yang memiliki pemikiran yang terbuka, skeptis terhadap ilmu pengetahuan baru, dan memiliki rasa ingin tahu yang tinggi terhadap pengetahuan atau informasi yang teruji kebenarannya. Instrumen yang digunakan dalam penelitian ini adalah critical thinking disposition scale yang terdiri dari 3 aspek yag dikemukakan oleh Ricketts and Rudd yaitu engagement, cognitive maturity, dan innovativeness dengan 23 item.

Information literacy adalah kemampuan mengakses, mengidentifikasi, mengevaluasi informasi yang didapatkan agar tidak terjadi kesalahan dalam pengambilan informasi dan mengambil informasi sesuai dengan kebutuhan atau secara bijaksana. Instrumen yang digunakan dalam penelitian ini adalah information literacy scale adaptasi dari Alfi Mufida Ahmad pada tahun 2017 dengan 13 item.

Kedua alat ukur dalam penelitian ini menggunakan skala likert yang disusun dengan cara item yang mendukung konsep (favorable) dan item yang tidak mendukung konsep (unfavorable). Setiap item pada kelompok pernyataan tersebut mempunyai empat pilihan jawaban yaitu : Sangat Sesuai (SS), Sesuai (S), Tidak Sesuai (TS), dan Sangat tidak sesuai (STS). Secara jelas dirincikan sebagai berikut: sangat setuju diberikan nilai 4, setuju diberikan nilai 3, tidak setuju diberikan nilai 2, dan sangat 
tidak setuju diberikan nilai 1 . Untuk critical thinking disposition dikatakan tinggi jika memiliki skor $>74$, sedang 66-74, dan rendah $<66$, Sedangkan iformation literacy dapat dikatakan tinggi jika memiliki skor $>41$, sedang 37-41, dan rendah $<37$.

Penelitian yang akan dilakukan terbagi dalam tiga tahap, yaitu tahap persiapan, tahap pelaksanaan, dan tahap analisa. Tahap persiapan dimulai dari peneliti melakukan pendalaman materi melalui kajian teoritik, Peneliti menyusun dan mengembangkan alat ukur berdasarkan aspek dalam variabel, selanjutnya peneliti meminta izin untuk melakukan penelitian (pengambilan data). Peneliti menggunakan uji coba atau try out pada 50 jumlah subjek dengan karakteristik mahasiswa. Selanjutnya peneliti melakukan analisis data menggunakan Statistical Package For Social Sciense (SPSS) 25 untuk mendapatkan item valid dan reliabel. Tahap pelaksanaan, peneliti menyebarkan skala critical thinking disposition dan skala information literacy yang telah dimodifikasi oleh peneliti. Alat ukur disebarkan kepada subjek sesuai dengan kriteria yang ditentukan peneliti sebanyak 269 subjek. Terakhir, tahap analisa yaitu menganalisa hasil yang didapatkan dari penyebaran dua skala kepada para subjek. Data-data yang telah diperoleh kemudian diinput dan diolah dengan menggunakan program perhitungan statistik SPSS 25, yaitu analisis korelasi linier sederhana.

\section{HASIL}

Subjek yang terdapat pada penelitian ini adalah 269 mahasiswa. Subjek dalam penelitian ini berusia 18-24 tahun. Berikut ini adalah data demografis yang didapatkan oleh peneliti.

Tabel 1. Data Demografi Partisipan

\begin{tabular}{ccc}
\hline Usia & Laki-laki & Perempuan \\
\hline $19-21$ & $50(63,3 \%)$ & $151(83,1 \%)$ \\
$22-24$ & $29(36,7 \%)$ & $39(20,5 \%)$ \\
& & \\
\hline Critical Thinking Disposition & Laki-laki & Perempuan \\
\hline Rendah & $20(7,4 \%)$ & $54(20,1 \%)$ \\
Sedang & $27(10,0 \%)$ & $51(19,1 \%)$ \\
Tinggi & $32(11,9 \%)$ & $85(31,6 \%)$ \\
Total & $\mathbf{7 9 ( 2 9 , 4 \% )}$ & $\mathbf{1 9 0}(\mathbf{7 0 , 6} \%)$ \\
\hline Information Literacy & Laki-laki & Perempuan \\
\hline Rendah & $20(7,4 \%)$ & $51(19,0 \%)$ \\
Tedang & $37(13,8 \%)$ & $85(31,6 \%)$ \\
& $22(8,2 \%)$ & $54(20,1 \%)$ \\
Total & & \\
\hline
\end{tabular}

Berdasakan pada tabel di atas menunjukkan data demogafis berupa usia 19-21 tahun laki-laki 50 mahasiswa $(63,3 \%)$ dan perempuan 151 (83,1\%). Usia 22-24 tahun 
laki-laki 29 mahasiswa (36,7\%) dan perempuan 39 mahasiswa (20,5\%). Laki-laki yang memiliki critical thinking disposition rendah sebanyak 20 mahasiswa $(11,9 \%)$, sedang sebanyak 27 mahasiswa (10,0\%), dan tinggi 32 mahasiswa (11,9\%). Sedangkan perempuan yang memiliki critical thiking disposition yang tinggi sebanyak 85 mahasiswa $(31,6 \%)$, sedang 51 mahasiswa $(19,1 \%)$, dan yang rendah 54 mahasiswa $(20,1 \%)$. Laki-laki yang memiliki nformation literacy yang rendah sebanyak 20 mahasiswa $(7,4 \%)$, sedang 37 mahasiswa (13,8\%) dan yang tinggi 22 mahasiswa $(8,2 \%)$. Sedangkan perempuan yang memiliki iformation literacy yang rendah sebanyak 51 mahasiswa $(19,0 \%)$, sedang 85 mahasiswa $(31,6 \%)$, dan tinggi 54 mahasiswa $(20,1 \%)$.

Tabel 2. Kategorisasi berdasarkan usia

\begin{tabular}{cccc}
\hline Critical thinking disposition & Rendah & Sedang & Tinggi \\
\hline Usia & & & \\
$19-21$ & 56 & 58 & 87 \\
$22-24$ & 18 & 20 & 30 \\
\hline Information Literacy & Rendah & Sedang & Tinggi \\
\hline Usia & & & \\
$19-21$ & 54 & 88 & 59 \\
$22-24$ & 17 & 34 & 17 \\
\hline
\end{tabular}

Tabel 2 pada usia 19-21 yang memiliki critical thinking disposition yang rendah sebanyak 56 mahasiswa, yang sedang 58 mahasiswa dan yang tinggi 87 mahasiswa. Sedangkan pada usia 22-24 yang memiliki critical thinking disposition yang rendah sebanyak 18 mahasiswa, yang sedang 20 mahasiswa dan yang tinggi 30 mahasiswa. Pada usia 19-21 yang memiliki information literacy yang rendah sebanyak 54 mahasiswa, yang sedang 88 mahasiswa dan yang tinggi 59 mahasiswa. Sedangkan pada usia 22-24 yang memiliki information literacy yang rendah sebanyak 17 mahasiswa, yang sedang 34 mahasiswa dan yang tinggi 17 mahasiswa.

Tabel.3 Hasil uji korelasi

\begin{tabular}{ccc}
\hline Variabel & $\mathbf{r}^{2}$ & $\mathbf{P}$ \\
\hline $\begin{array}{c}\text { Critical Thinking Disposiion - Information } \\
\text { Literacy }\end{array}$ & 0,621 & 0,000 \\
\hline
\end{tabular}

Berdasarkan pada uji kenormalan dengan menggunakan skewness kurtosis bahwa data tersebut dapat dikatakan normal apabila data tersebut memiliki nilai skewness kurtosis pada kedua variabel berada pada -2 dan 2. Nilai skewness pada CTD didapatkan hasil pembagian dari nilai statistik sebesar 0,244 dan std error 0,149 adalah 1,637. Nilai kurtosis IL didapatkan dari hasil pembagian dari nilai statistic 0,075 dan std error 0,149 adalah 0,503.

Berdasarkan dari analisis data, Hasilnya adalah 0,00<0,05 yang artinya ada hubungan signifikan antara critical thinking disposition dan information literacy, dengan arah hubungan berdasarkan pearson correlation 0,621 yang artinya hubungan antara 
critical thinking disposition dan information literacy adalah memiliki hubungan yang signifikan. Nilai $\mathrm{r}^{2}$ merupakan nilai koefisien determinasi yaitu antara 0 dan 1 , Nilai $\mathrm{r}^{2}$ yang kecil berarti variasi variable dependent yang sangat terbatas dan nilai yang mendekati 1 berarti variabel-vaiabel independent sudah dapat memberi semua informasi yang dibutuhkan untuk memprediksi variabel dependent. Nilai $\mathrm{r}^{2}$ pada penelitian ini adalah, 0,621 yang artinya variabel critical thinking disposition dapat memberi semua informasi yang dibutuhkan untuk memprediksi variabel information literacy.

\section{DISKUSI}

Hasil penelitian yang telah dilakukan, didapatkan hasil uji korelasi yaitu sebesar $0,00<0,05$. Hal ini menunukkan bahwa ada korelasi yang positif antara critical thinking disposition dengan information literacy, Semakin tinggi critical thinking disposition maka information literacynya pun tinggi, begitu pula sebaliknya. Jika critical thinking dispositionnya rendah maka information literacynya pun rendah. Pada penelitian sebelumnya tentang critical thinking disposition, bahwa critical thinking disposition dapat ditingkatkan melalui model pembelajaran bermakna dengan berbagai aspek yaitu innovativeness, cognitive maturity, critical subjectivity, engagement dan reflective sceptisme dari 22 mahasiswa ada 12 mahasiswa mengalami peningkatan critical thinking disposition yang signifikan (Wilda, 2019). Penelitian lain yang dilakukan oleh Sulaiman (2018), menunjukkan bahwa critical thinking disposition dapat ditingkatkan melalui peningkatan metakognisi dan regulasi berpikir kritis siswa dengan dibantu sebuah tabel.

Critical thinking disposition adalah kecenderungan untuk bersikap kritis terhadap sebuah informasi atau ilmu pengetahuan (Ormrod, 2008; Sulaiman \& Nandy). Sesuai dengan hasil penelitian yang dilakukan oleh peneliti, ketika mahasiswa memiliki critical thinking disposition yang baik maka mahasiswa tersebut memiliki information literacy yang baik pula. Jika mahasiswa memiliki critical thinking disposition yang baik, maka dia akan berusaha utuk mencari sumber informasi dan ilmu pengetahuan lain untuk mengkombinasikan antara informasi satu dengan informasi lainnya.

Di era digital ini dengan banyaknya informasi yang didapat oleh mahasiswa melalui media sosial, seharusnya membuat mahasiswa harus bisa lebih mengkritisi informasi tersebut dan memiliki pemikiran yang terbuka, agar mahasiswa lebih punya banyak sumber informasi yang akan diberikan ataupun yang akan dia terima dan tidak terkena berita hoax yang ada di media sosial.

Peran mahasiswa yang memiliki pemikiran terbuka terhadap suatu informasi, lalu mencari sumber yang jelas dari sebuah informasi atau ilmu pengetahuan yang ia dapatkan, lalu mengidentifikasi kembali apakah sumber yang ia dapatkan dari sumber terpercaya atau sumber yang ia dapatkan ternyata hoax. Kemampuan information iiteracy di era digital dan informasi yang tersebar luas di media sosial menjadi sangat penting, karena menurut hasil penelitian kemampuan information literacy ditinjau dari usia tergolong sedang, namun yang rendahpun juga banyak, oleh sebab itu penting sekali memang kemampuan information literacy di era digital dan informasi yang semua serba ada di media sosial. Perempuan bahkan lebih tinggi critical thinking dispositionnya dibanding dengan laki-laki, karena perempuan lebih memiliki 
kematangan emosi yang baik dan lebih dapat berpikir jernih dibanding laki-laki (Hurlock, 1996). Pada penelitian sebelumnya menjelaskan bahwa pentingnya information literacy pada siswa SMA Lab School Kebayoran, Terjadinya peningkatan information literacy pada siswa ditinjau dari beberapa aspek yaitu pemanfaatan informasi, mengevaluasi informasi, dan mencari referensi informasi (Mufida, 2017).

Berdasarkan penjabaran di atas, bahwa antara critical thinking disposition dengan information literacy memiliki hubungan yang signifikan, dan ditinjau dari segi kategori jenis kelamin serta usia critical thinking disposition dan information literacy memang sangat berpengaruh bagi mahasiswa dalam menerima ataupun mengambil sebuah informasi ataupun ilmu pengetahuan melalui sumber-sumber yang ada di media sosial.

\section{SIMPULAN DAN IMPLIKASI}

Berdasarkan hasil penelitian yang dilakukan oleh peneliti, bahwa hipotesa penelitian ini diterima yang artinya penelitian hubungan antara critical thinking dan information literacy memiliki hubungan yang signifikan positif $(0,00<0,05)$. Implikasi dari penelitian ini ditujukan kepada para mahasiswa yang memiliki peran intelektual baik di kampus maupun di masyarakat agar lebih banyak belajar dan membaca banyak referensi informasi, agar mahasiswa dapat menjadi pemberi informasi yang baik terhadap masyarakat, lalu dapat mengkritisi sebuah informasi untuk mencari kebenaran ataupun validitas informasi yang mereka dapat dengan mencari sumber informasi yang lebih banyak. Selain itu juga untuk meningkat mutu pendidikan yang sudah ada melalui peran mahasiswa yang ikut memberikan andil dalam pendidikan berpikir kritis yang ada di kampus maupun di masyarakat.

Untuk para pengajar bisa lebih memperhatikan sumber buku bacaan dan informasi yang mereka dapatkan, agar informasi yang mereka dapatkan mudah dipahami oleh siswa ataupun mahasiswanya dengan berbagai macam sumber informasi yang banyak dan sumber yang terpercaya, dan dapat memberikan ilmu pengetahuan baru namun sesuai dengan permasalahan yang ada di masyarakat agar mahasiswanya dapat menganalisis juga permasalahan-permasalahan yang terjadi di masyarakat.

Kelemahan dalam penelitian ini yang harus diperbaiki oleh peneliti selanjutnya adalah diharapkan dapat menambah jumlah subjek mahasiswa dan lebih spesifik untuk kategori mahasiswanya, semisal mahasiswa organisatoris dengan mahasiswa kuliah-pulang atau antara mahasiswa Indonesia dengan mahasiswa asing, agar mendapatkan hasil penelitian yang kaya dan beragam. Secara metodologi penelitian ini bisa dikembangkan lagi, salah satunya dengan menggunakan studi kasus sehingga kita dapat melihat hasilnya secara langsung.

\section{REFERENSI}

Abdurrahman, M. (2007). Pendidikan Bagi Anak Berkesulitan Belajar. Jakarta : Rineka Cipta. Abrami. (2015). Strategies for Teaching Students to Think Critically: A Meta-Analysis.

Ahmad, Alfi M. (2017). Peran Pustakawan dalam Meningkatkan Literasi Informasi di SMA LAB School Kebayoran. Jakarta. UIN Jakarta.

Ahmatika, D. (2015). Peningkatan Kemampuan Berfikir Kreatif Matematis dan Self-Confidence Siswa SMP melalui Resources-Based Learning (RBL) dengan Pendekatan Saintifik. (Tesis). Sekolah 
Pascasarjana, Universitas Pendidikan Indonesia, Bandung : Sekolah Pascasarjana, Universitas Pendidikan Indonesia

Bruce, C. (2003). Seven faces of information literacy towards inviting students int new experience. http://crm.hct.ac.ae/events/archive/2003/speakers/bruce.pdf

Bundy, A. (2001). For a clever Country: infrormation literacy diffussion in the 21st century. http://www.library.unisa.edu.au/about/papers/clever.pdf.

Facione, P. A. (2011). Critical Thinking: What It Is and Why It Counts. Insight Assessment, (ISBN 13: 978-1-891557-07-1.), 1-28. https://doi.org/ISBN 13: 978-1891557-07-1

Halstead, J. Mark (2004) An Islamic concept of education. Comparative Education.

Hartaji, D.A. (2012). Motivasi Berprestasi Pada Mahasiswa yang Berkuliah Dengan Jurusan Pilihan Orangtua. Fakultas Psikologi Universitas Gunadarma.

Kompas.(2018).https://tekno.kompas.com/read/2018/03/01/10340027/riset-ungkap-polapemakaian-medsos-orang-indonesia. Diakses Rabu, 08 Mei 2019 Pukul 23.52 WIB.

Kupang Pos. (2019). http://kupang.tribunnews.com/2016/08/25/keharusan-berpikir-kritis-bagimahasiswa. Diakses pada Jumat, 8 Februari 2019.

Kupang Pos. (2016). http://kupang.tribunnews.com/2016/08/25/keharusan-berpikir-kritis-bagimahasiswa. Diakses pada Jumat, 8 Februari 2019.

Liliasari \& Gunawan, (2012).Model Virtual Laboratory Fisika Modrn Untuk Mingkatkan Disposisi Berpikir Kritis Calon Guru. Jurnal. [Online]. Tersedia: http://www.lppmp.uny.ac.id.

Martika, D. (2017) Pengaruh Konsep Diri Terhadap Kemampuan Berpikir Kritis Siswa (Survey Pasa Siswa IPS Kelas XI SMA Negeri 22 Bandung). Skripsi(S1) thesis. Bandung : FKIP Unpas.

Miller. (2017). An assessment of critical thinking: can pharmacy students evaluate clinical studies like experts?. Pharm Educ.

Macnamara, J. (2014). Media mana yang menentukan pemberitaan Media massa atau dan media sosial Sebuah Laporan Penelitian, Sentia.

Mulyono, H. (2015). Literasi Informasi dan Kritis: Urgensi, Perspektif Islam, dan Integrasi dalam Kurikulum Pendidikan. Jakarta : Tarbiyah XXII.

Muin. (2018). The effect of creative problem solving on students' mathematical adaptive reasoning. Journal of Phsyics Conferences series.

Naghfiroh. (2016). Literasi Informasi Mahasiswa Teknik (Studi Deskriptif Tentang Literasi Informasi pada Mahasiswa Teknik di Institut Teknologi Sepuluh Nopember Surabaya). Skripsi thesis. Surabaya : Universitas Airlangga.

Ormrod, J. E. (2008). Psikologi Pendidikan: Membantu Siswa Tumbuh dan Berkembang. Jakarta: Penerbit Erlangga

Paparistodemou.(2008). Developing young children's informal inference skills in data analysis. Statistics Education Research Journal.

Ricketts, J. D., \& Rudd, R. D. (2010). Critical thinking skills of selected youth leaders: The efficacy of critical thinking dispositions, Leadership, and academic performance. Journal of Agricultural Education, 46(1), 32-43. https://doi.org/10.5032/jae.2005.01032.

Rimiene, V. (2002). Assessing and developing students' critical thinking. Dalam Psychology Learning and Teaching, Vol. 2(1), 17-22.[Online]. Tersedia: http://www.heacademy.ac.uk/assets/documents/subjects/psychology/2-1-rimiene.pdf.

Sari, Wilda K. (2019). Penerapan Model Pembelajaran Bermakna dalam Meningkatkan Disposisi Berpikir Kritis. Malang. Fakultas Psikologi Universitas Muhammadiyah Malang.

Sanjaya, W.(2008). Perencanaan dan desain sistem pembelajaran. Jakarta: Kencana Prenada Media Group.

Silvana, T. (2017). Studi Tentang Kemampuan Literasi Informasi Di Kalangan Siswa Menengah Pertama. Bandung :Universitas Padjajaran.

Siswoyo, Dwi. (2007). Ilmu Pendidikan. Yogyakarta : Universitas Negeri Yogyakarta. 
Sosu, E. M. (2013). The development and psychometric validation of a Critical Thinking Disposition Scale. Thinking Skills and Creativity, 9, 107-119. doi:https://doi.org/10.1016/j.tsc.2012.09.002

Sulaiman, A., \& Syakarofath, N. A. Berpikir Kritis: Mendorong Introduksi dan Reformulasi Konsep dalam Psikologi Islam. Buletin Psikologi, 26(2), 86-96.

Sulaiman, A. (2018). Critical-thinking assessment table: a novel strategy to foster students' critical thinking dispositions. Jurnal Ilmiah Psikologi Terapan, 6(2), 178-193.

Wijayanti. (2012). Kemampuan Literasi Informasi siswa di SMP Negeri 4 Depok. Skripsi diterbitkansecara online. Jakarta: Universitas Indonesia.

Webber, S. (2010). Information Literacy for the 21st Century. INFORUM 2010 : 16th Conference on Professional Information Resources. Praha. 25-27 Mei 2010. $<$ http://www.inforum.cz/pdf/2010/webber-sheila-1.pdf> 